\title{
Community Response to Public Health Emergency and Thoughts on Improving the Resilience of Community Planning:
}

\author{
A Case Study of Beijing, Shanghai, Guangzhou and Shenzhen \\ based on online News
}

Yue ZENG, Chengdu Jiuhe United Urban Planning \& Design Co., Ltd., China

\begin{abstract}
Communities are the front lines facing Covid-19, in addition to city entrances. This paper uses four mega cities in China as the cases, which are Beijing, Shanghai, Guangzhou and Shenzhen. It uses a text-mining method to express online news about the anti-Covid-19 measures of communities in these case cities, and conducts a qualitative research on 1207 press releases, which are published by official media, institutions and self-media from January 2020 to September 2020. According to the analysis, the main anti-Covid-19 measures in community level include strengthening publicity by using mobile social media; clarifying the situation of every household; intensifying the management of neighbourhood entrance; upgrading epidemic prevention and public health management; cooperation with all social forces; shortening the distance between daily necessities and residents, and preliminary applications of smart technology. On this basis, this article attempts to propose thoughts on enhancing community resilience, including orienting from space to human; using mobile social network apps to promote public participation; enhancing the flexibility of community planning; integrating risk management thinking into community planning and refining community governance with the help of smart technology.
\end{abstract}

\section{Keywords}

Mega Cities; Text-mining Method; Community Resilience; Community Planning

\section{Introduction}

The word "resilience" is derived from the Latin word "resilio", which originally means the ability of an object to recover its size and shape after being deformed under pressure. After being applied to ecosystem research by ecologist C. S. Holling, this concept have caused widespread concern as it is more suitable for facing our currently complex and changing social and nature environment than the word "sustainable", and then been introduced into the field of urban planning. Comparing a city to a living body, "resilience" is like its immunity system. Cities need to not only provide an environmental conducive to both physical and mental health of its residents, but also the ability to respond to sudden disturbances at any time. As the basic unit of urban life and grassroots governance, community is regarded as a typical representative of urban resilience, and has been a hot topic in resilience research in recent years. Currently, there is no unified definition for community resilience. Most studies believe that community 
resilience refers to the ability of quick resources allocation, minimize the impact of disasters, and adapt to changes when facing crisis.

The pandemic of COVID-19 in 2020 is a concentrated test for the resilience of all the urban and rural areas, and communities are the main battlefields besides city entrances. As the basic constituent unit of community, the self-organizing ability demonstrated by neighbourhoods during this epidemic is an excellent demonstration of community resilience, and also an important reference for the building of community resilience and governance capacity. Among them, densely populated mega cities face greater risks. Slightly untimely or inappropriate handling may quickly evolve rapid spread of disasters. Therefore, the study of community resilience in megacities is of great significance. Until now, the epidemic prevention response of communities in China has provides a relatively convincing answer, and with many original practices. This paper uses four mega cities in China as the cases, which are Beijing, Shanghai, Guangzhou and Shenzhen, all of them have more than 13 million residents, including more than 7 million flowing population. It uses a text-mining method to express online news about the anti-Covid-19 measures of communities in these cities, conducts a qualitative research and attempts to summarize the main anti-Covid-19 measures and propose thoughts on enhancing community resilience.

\section{Overall situation of epidemic prevention in Beijing, Shanghai, Guangzhou and Shenzhen}

According to information from the health commissions of these four cities, by September 30, 2020, Beijing has reported a total of 759 local confirmed cases and 177 imported ones; Shanghai has reported 342 local confirmed cases and 664 imported ones; Guangzhou has reported349 local confirmed cases and 344 imported ones; Shenzhen has reported 423 local confirmed cases and 48 imported ones. As almost all the imported confirmed cases have been chauffeured to hospitals for isolation directly after they got off the planes, there is no staying place of them inside the city. All four cities have announced the staying places of confirmed cases. Beijing announced 130 stays, including 124 communities; Shanghai announced 87 stays, including 48 communities; Guangzhou announced 231 stays, including 105 communities; Shenzhen announced 245 stays, including 215 communities. Their spatial distributions are shown in Figure 1.

\section{Research method}

This paper uses Rost Content Mining software as the text-mining tool to extract the high-frequency words in the community anti-Covid-19 news in case cities. Details are as follows:

\subsection{Texts collection}

1) Using "city name + community+ anti-epidemic" and names of neighborhoods with confirmed cases as the keywords on both web pages and WeChat self-media pages.

2) In the same city, if the articles contents are almost the same but by different publishers, take only one;

3) Articles with similar topic, for example introducing similar smart technology machine, although at different location, take only one;

4) Ultimately, collected 339 articles about Beijing with 425,667 Chinese characters; 272 articles about Shanghai with 359,457 Chinese characters; 395 articles about Guangzhou with 470,384 Chinese characters and 201 articles about Shenzhen with 351,419 Chinese characters. A total of 1207 articles, about 1.6 million $(1,606,927)$ characters, with the time span from January 21, 2020 to September 20, 2020 have been collected. Releasing agencies are listed in Table 1. 

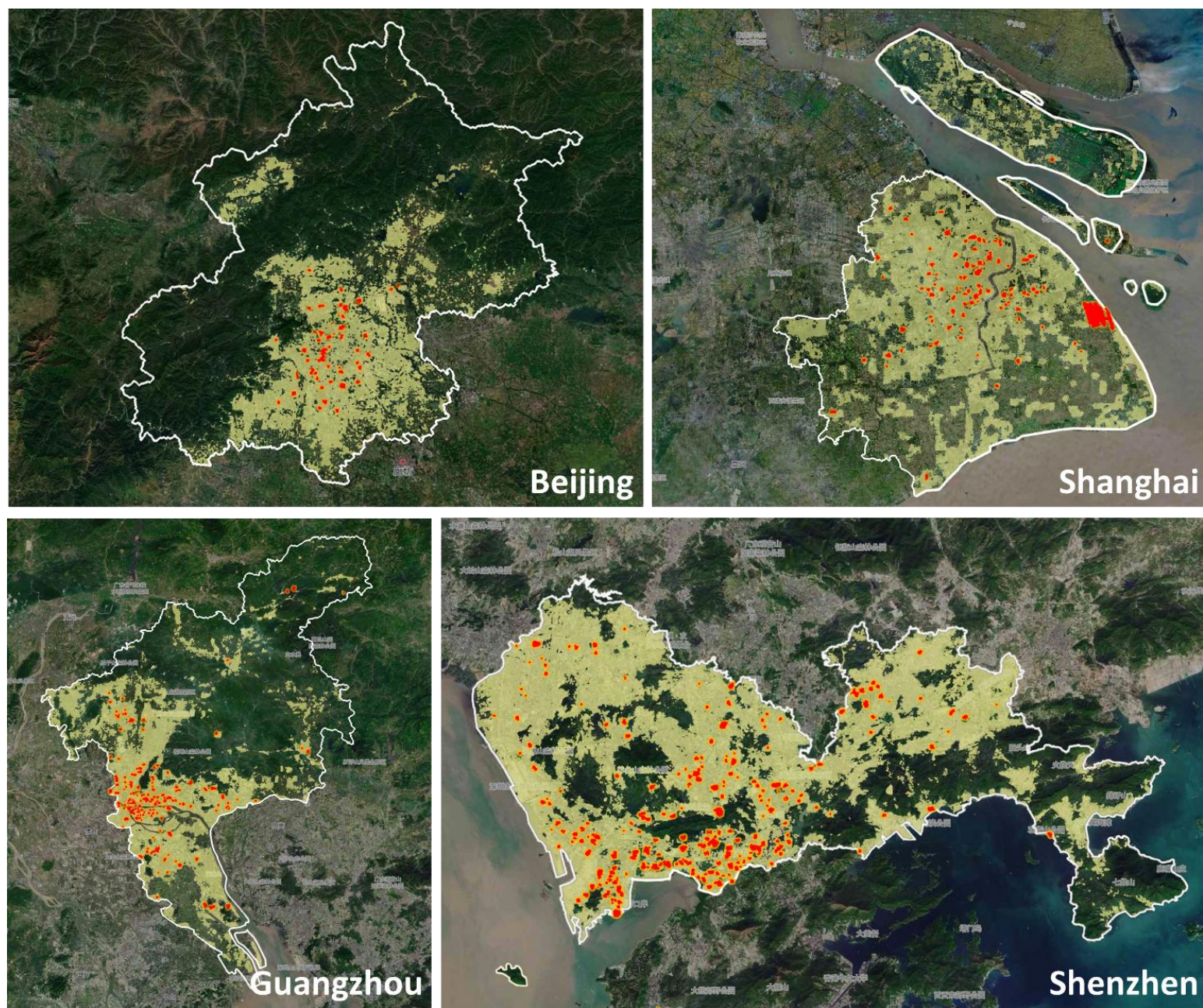

Figure 1: Stayed places of local confirmed cases. The white line is the city boundary, the red dots are the places where the local confirmed cases have stayed, and the yellow areas are the built-up areas. Source: SELF-DRAWN BASED ON EPIDEMIC MAP OF AMAP.COM.

\subsection{Texts segmentation}

Use the word segmentation function of Rost Content Mining to segment the texts, check the meanings of phrases after segmentation, and add new phrases used in the anti-Covid-19 articles in the database. Then re-segment the texts and extract the high-frequency words, and check again whether most of the segmented words have semantics meanings in accordance with the background of the articles. Ensure at least the first $20 \%$ words after segmentation are meaningful. After many repetition, finally get 12,927 phrases in articles about Beijing, 11,925 in articles about Shanghai, 11,317 in articles about Guangzhou, and 9,559 in articles about Shenzhen.

Table 1. Sources and Statistics of news in 4 case cities

\begin{tabular}{lrrrrr}
\hline News Sources & Beijing & Shanghai & Guangzhou & Shenzhen & Total \\
\hline $\begin{array}{l}\text { Property } \\
\text { management } \\
\text { team }\end{array}$ & 4 & 12 & 54 & 61 & 131 \\
\hline $\begin{array}{l}\text { Official news from } \\
\text { District and }\end{array}$ & 221 & 165 & 275 & 47 & 708 \\
\hline
\end{tabular}




\begin{tabular}{|c|c|c|c|c|c|c|}
\hline \multirow[t]{4}{*}{ media } & \multicolumn{6}{|l|}{ Community level } \\
\hline & Municipal level & 32 & 46 & 24 & 64 & 166 \\
\hline & National level & 33 & 9 & 14 & 15 & 71 \\
\hline & $\begin{array}{l}\text { Municipal media of } \\
\text { other city }\end{array}$ & 2 & 2 & 1 & 1 & 6 \\
\hline \multirow{2}{*}{$\begin{array}{l}\text { Official news from } \\
\text { authorities }\end{array}$} & Municipal level & 10 & 6 & 9 & 0 & 25 \\
\hline & District level & 14 & 19 & 3 & 0 & 36 \\
\hline \multirow[t]{2}{*}{ Self-media } & company & 17 & 9 & 10 & 9 & 45 \\
\hline & personal & 6 & 4 & 5 & 4 & 19 \\
\hline number of articles & & 339 & 272 & 395 & 201 & 1207 \\
\hline number of & & 425667 & 359457 & 470384 & 351419 & 1606 \\
\hline Chinese & & & & & & 927 \\
\hline characters & & & & & & \\
\hline
\end{tabular}

\subsection{Words frequency analysis}

In order to improve the accuracy of analysis, based on the meaning of the words in the contents, unify the words with similar semantics. For example, unify "disinfection", "elimination", "disinfectant", "hand sanitizer", "alcohol", etc. as "disinfection"; unify "propaganda", "posters", "banners", "broadcasting", etc. as "propaganda"; unify "express", "takeaway", "express cabinet", and "contactless delivery" as " Express delivery"; unify "smart technology", "drone", "face recognition", etc. are unified as "smart technology";

As the number of articles varies from city to city, standardize the word frequency by:

$$
\mathrm{N}^{\prime}{ }_{\mathrm{a}}=\mathrm{N}_{\mathrm{a}} \times 100 / \mathrm{N}_{\max }
$$

$\mathrm{N}_{\mathrm{a}}$ represents the frequency of occurrence of a word in articles of one city; $\mathrm{N}_{\max }$ represents the maximum word frequency in the articles of that city; $\mathrm{N}_{\mathrm{a}}$ represents the standardized word frequency score of that word. Take the top $5 \%$ of the words as samples, which are about 50 words, and can be seen in Figure 2.
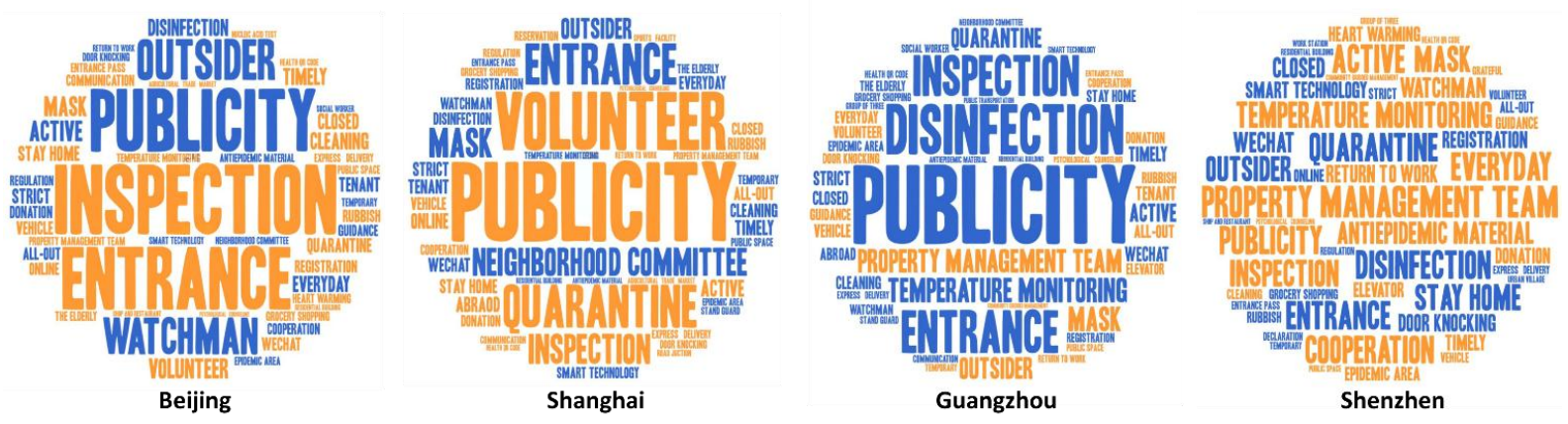

Figure 2. Top high-frequency words in community anti-Covid-19 articles of 4 case cities. Source: SELFDRAWN WITH WEICIYUN.COM. 


\section{Research result}

Add the same high-frequency words together and divide them into 5 categories by measures, participants, locations, items and modifier words like adjectives and adverbs, and sort out the most used ones, which can be seen in Table 2 and Figure 3.

Table 2. Top high-frequency words in community anti-Covid-19 articles in 4 cities

\begin{tabular}{|c|c|c|c|c|}
\hline & High frequency words in 4 cities & $\begin{array}{l}\text { High frequency } \\
\text { words in } 3 \text { cities }\end{array}$ & $\begin{array}{l}\text { High frequency } \\
\text { words in } 2 \text { cities }\end{array}$ & $\begin{array}{l}\text { Unique } \\
\text { high- } \\
\text { frequency } \\
\text { words }\end{array}$ \\
\hline $\begin{array}{l}\text { Measure } \\
\text { s }\end{array}$ & $\begin{array}{l}\text { publicity (327.51), inspection(252.84), } \\
\text { disinfection(236.74), } \\
\text { quarantine(228.94), temperature } \\
\text { monitoring(189.46), stay } \\
\text { home(172.62),registration(154.66), } \\
\text { smart technology(133.06), } \\
\text { cooperation(129.67), door } \\
\text { knocking(128.33), grocery } \\
\text { shopping(126.53.00), cleaning(116.52), } \\
\text { psychological counseling(88.21), } \\
\text { WeChat(87.77), closed(77.85), } \\
\text { donation(71.03), health QR code(52.84) }\end{array}$ & $\begin{array}{l}\text { communication( } \\
\text { 103.73),guidanc } \\
\text { e(42.96), regulat } \\
\text { ion(34.25), } \\
\text { online(32.69) }\end{array}$ & $\begin{array}{l}\text { community } \\
\text { gridded } \\
\text { management( } 21 . \\
27)\end{array}$ & $\begin{array}{l}\text { reservation( } \\
24.38), \text { nucle } \\
\text { ic acid } \\
\text { test(20.74), } \\
\text { declaration( } \\
12.20)\end{array}$ \\
\hline $\begin{array}{l}\text { Participa } \\
\text { nts }\end{array}$ & $\begin{array}{l}\text { property management team(246.77), } \\
\text { outsider(214.09), volunteer(193.45), } \\
\text { watchman(161.70) }\end{array}$ & $\begin{array}{l}\text { neighborhood } \\
\text { committee(128. } \\
38), \text { the } \\
\text { elderly(80.91), } \\
\text { tenant(56.46) }\end{array}$ & $\begin{array}{l}\text { social } \\
\text { worker(43.61), } \\
\text { group of } \\
\text { three(25.64),stan } \\
\text { d guard(22.55), }\end{array}$ & \\
\hline $\begin{array}{l}\text { Location } \\
\mathrm{s}\end{array}$ & $\begin{array}{r}\text { entrance(255.18), epidemic } \\
\text { place(105.71), residential } \\
\text { building(61.44), public space(43.13) }\end{array}$ & & $\begin{array}{l}\text { agricultural trade } \\
\text { market(49.87),abr } \\
\text { oad(44.56), } \\
\text { elevator(30.80),sh } \\
\text { op and } \\
\text { restaurant(21.95) }\end{array}$ & $\begin{array}{l}\text { public } \\
\text { transportati } \\
\text { on(15.96), } \\
\text { urban } \\
\text { village(11.7 } \\
\text { 3), road } \\
\text { junction(9.6 } \\
\text { 3), work } \\
\text { station(9.10 } \\
\text { ) }\end{array}$ \\
\hline Items & $\begin{array}{r}\text { mask(154.71), express delivery(129.01), } \\
\text { anti-epidemic material(116.18), } \\
\text { entrance pass(96.11), } \text { rubbish(64.88), } \\
\text { vehicle(51.35) }\end{array}$ & & & $\begin{array}{l}\text { sports facilit } \\
\mathrm{y}(16.43)\end{array}$ \\
\hline $\begin{array}{l}\text { Adjectiv } \\
\text { es } \& \\
\text { adverbs }\end{array}$ & $\begin{array}{r}\text { active(158.22), everyday(138.60), } \\
\text { timely(103.15), comprehensive(80.54), } \\
\text { strict(60.33), return to work*(85.43), } \\
\text { temporary(46.97) }\end{array}$ & & $\begin{array}{l}\text { heartwarming }(45 . \\
\text { 38) }\end{array}$ & $\begin{array}{l}\text { grateful(9.7 } \\
7)\end{array}$ \\
\hline
\end{tabular}

* "return to work" here refers to a kind of situation. 


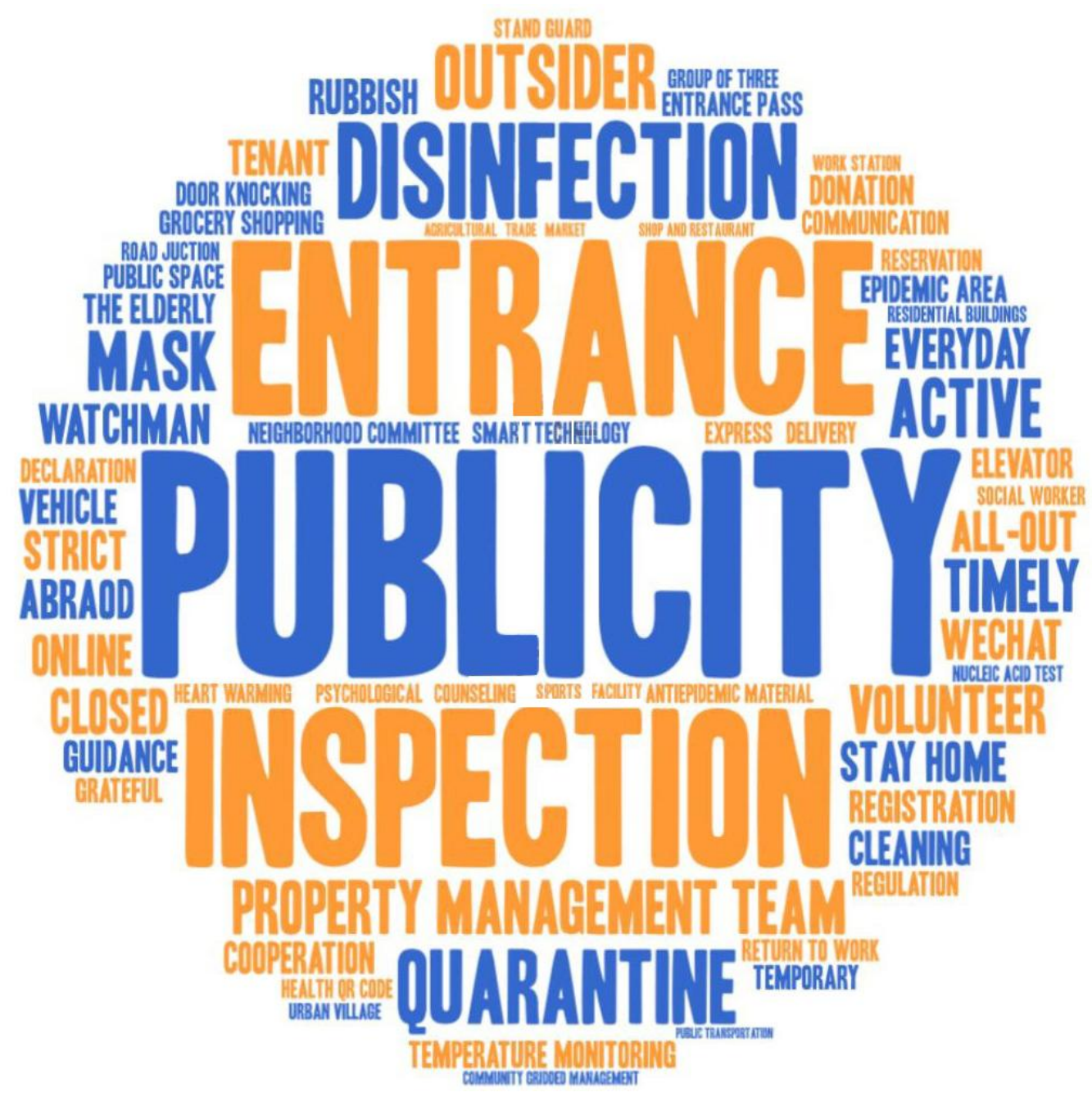

Figure 3. Top high-frequency words in community anti-Covid-19 articles in 4 case cities. Source: SELFDRAWN WITH WEICIYUN.COM.

\section{Major anti-Covid-19 measures in community level}

\subsection{Strengthen publicity by using mobile social media}

"Publicity" is the top frequency word with a score of 371.51 out of 400 , which means it is of highly importance in all cases. Meanwhile, the frequency of "WeChat" also reaches 87.77. In this anti-epidemic campaign, chatting groups set up by property management team and neighborhood committee, together with articles published by them on WeChat self-media, just-in-time epidemic information releasing on Weibo, and self-directed videos on TikTok, etc., have built a in time communication network between the community managers and residents. Almost every require could be met and many kinds of activities are organized on these social medias, and the relationship between community managers and residents, residents and residents has been much improved. For example, residents can leave messages in WeChat chatting group, from buying masks, daily necessities and OTC medicines to attending balcony concerts, online chorus, cooking competitions, online sports games etc,. Many neighborhoods have also added psychologists in the chatting group, and residents can consult them 24-hour. 


\title{
5.2 Clarify the travel route of every household and intensify the management of
}

\author{
neighbourhood entrances
}

"Inspection" is the second top frequency word, with a score of 252.84. Related words include "registration", "entrance", "door-to-door", "entrance pass", etc., with the scores of 154.66, 255.18, 128.33 and 96.11 . The travel routes of every resident was confirmed, especially those came from other cities or were visited by relatives or friends from other cities. Either property management team, neighborhood committee, community gridded management workers or volunteers made calls or door knocking visits to every household. Everyone was required to take body temperature monitoring and show his or her health QR code when entering a community. Different entrance passes for residents, delivery men and visitors were delivered. In neighborhoods with confirmed cases, People and vehicles not belonging to that community were not allowed to enter; in neighborhoods without confirmed cases, visitors could only enter with the pass. Activities outside one's living building are strictly limited to daily necessities purchase. And residential buildings which confirmed cases would be closed for 14 days. The daily necessities purchase and rubbish cleaning of these households were done by the community managing people mentioned above.

\subsection{Upgrade epidemic prevention and public health management}

"Disinfection" and "cleaning" are scored 236.74 and 116.52. Measures include disinfecting public areas 24 times a day, especially stairs, elevator halls and cars; setting up special masks recycling trash cans; covering elevator buttons with plastic wrap; installing ultraviolet disinfection lamps, and spraying disinfectant by drones etc.

\subsection{Cooperation with all social forces}

Volunteers played a very important role, with the score of 193.45. Many residents have voluntarily undertaken assistance work, such as data statistics, disinfectant spraying, stand guards, door-to-door delivery of daily necessities to the quarantine households etc. Many residents also donate anti-epidemic material and money to their communities and hospitals.

\subsection{Shorten the distance between daily necessities and residents}

Most residents stayed home during the epidemic, and buying food and other daily necessities were the only reason to go out. In order to reduce the risk of being infected during purchase in markets, many communities cooperated with agricultural markets and farmers, set "vegetable stalls" inside the neighborhoods. Some also invite professional hairdressers or volunteers to make haircut for residents.

\subsection{Preliminary applications of smart technology}

"Smart technology" has a score of 133.06. Many new facilities have been applied during this epidemic, including face recognition machine, temperature measurement of thermal imaging cameras, drones, driverless cars and etc.

\section{Thoughts on enhancing community resilience}

\subsection{From space-oriented to human-oriented}

In epidemic prevention and control, knowing the tracks of every person is the crucial point, so does in community planning. The demands of residents should be in the first place, instead of space, which is only the place holding activities. The abilities, skills and knowledge of residents are also considered as 
important human resources for improving community resilience. Under the impact of this unknown epidemic, many residents participated more actively in community affairs, and also proved that they have these abilities. Planners should make full use of this arising senses of community, use community planning as the platform to enhance public participation, assist communities to build neighborhood network, cultivate community spirit, and improve community governance.

\subsection{Use mobile social network apps to promote public participation}

During the epidemic, online communication represented by WeChat groups has become the most important communication method between community managers and residents, and has achieved sound effects. Planners can use mobile social network apps to share ideas more timely with residents, and residents can reply in spare minutes. Meanwhile, online discussions can save a lot of time cost, and therefore it is possible to invite more experts and social forces to work together on specific community issues.

\subsection{Enhance the flexibility of community planning}

Enhance community resilience does not mean to build a community without disaster, but to build a system that can adapt to various challenging changes, and has the ability of self-learning and selforganizing. Comparing to bigger areas, communities are more sensitive to outside influence. Planners need to stay focusing on new challenges and demands of communities, review and adjust in time, set aside more flexible planning indexes, and go through the whole dynamic cycle of preparation, response and reconstruction together with the community.

\subsection{Integrate risk management thinking into community planning}

This epidemic revealed the insufficiency of medical facilities treating infectious diseases in community level, but what the next risk will be like is completely unknown. On the one hand, community planning need to improve the facilities allocation and spatial layout after every emergency. On the other hand, community planning also need to do risk identification and evaluation in normal times, think about the possible situations under different risks and make multi-scenario planning.

\subsection{Refine community governance with the help of smart technology}

After a time of the outbreak of COVID-19, many cities have launched real-time COVID-19 comfirmed case stayed maps and health codes, and drivelss cars or drones havd been widely used. Smart technology can be a competitive assistant in risk management, not to mention in normal times. Communities can use techniques to integrate daily management work and establish their own residents databases and information platform.

\section{Conclusion}

The future changes rapidly, and we can never predict what the next risk will be and when it will happen. At the same time, the needs of society and people are constantly changing. The urban and rural living environment can only be improved, but can never reach a "perfect" condition. As an important aspect of healthy city, the realization of resilience in city level depends on the accumulation and transmission from community level. Only by increasing the reaction speed to the crisis, strengthening the self-organization ability of community, exerting the strength of every resident, can we form a resilient community and build resilient cities and countries. 


\section{References}

Huang, X. J, Huang X. (2015) 'Resilient City and its Planning Framework', City Planning Review, 39 (2), p5056.

Lin, P.Y, Wang, X.L. (2018) 'The Trend and Future Development of Research on Resilient City', Chinese Landscape Architecture, 8, p18-22.

Peng, C, Guo, Z.Y, Peng, Z.R. (2017) 'Research Progress on the Theory and Practice of Foreign Community Resilience', Urban Planning International, 32 (4), p60-66.

Shen, J.K, Wang, Y.C. (2018) 'Three Dimensions of Resilient Urban Community Planning and Design', Landscape Architecture, 12, p65-69.

Xiang, M.M, Gu, L.S, Han, Z.Q. (2016) 'A Review of the Development of Resilient Community Construction', Beauty \& Times, 7, p117-118.

Shen, J.K, Wang, Y.C. (2017) 'A Framework of Urban Community Planning and Design Based on the Characteristics of Resilience', Landscape Architecture, 3, p98-106.

Zeng, Y, Zhang, J. (2020) 'Thoughts on the Planning of Community Resilience Construction Based on Neighbourhood Anti-COVID-19 Measures under Public Health Emergencies: Taking Chengdu City as an Example', Journal of Human Settlements in West China, 35(3), p23-28. 